OPEN ACCESS

Edited by:

Yassine Taoufik,

Université Paris-Sud, France

Reviewed by:

David Clifford,

Washington University in

St. Louis, USA

Jacques Gasnault,

Bicetre University Hospital, France

*Correspondence:

Arnaud de La Blanchardière delablanchardiere-a@chu-caen.fr

Specialty section:

This article was submitted to Multiple Sclerosis and

Neuroimmunology,

a section of the journal

Frontiers in Immunology

Received: 22 December 2016 Accepted: 01 May 2017 Published: 23 May 2017

Citation:

Fournier A, Martin-Blondel G, Lechapt-Zalcman E, Dina J, Kazemi A, Verdon R, Mortier E and

de La Blanchardière A (2017) Immune Reconstitution Inflammatory Syndrome Unmasking or Worsening AIDS-Related Progressive Multifocal

Leukoencephalopathy:

A Literature Review.

Front. Immunol. 8:577.

doi: 10.3389/fimmu.2017.00577

\section{Immune Reconstitution Inflammatory Syndrome Unmasking or Worsening AIDS-Related Progressive Multifocal Leukoencephalopathy: A Literature Review}

\author{
Anna Fournier ${ }^{1}$, Guillaume Martin-Blondel ${ }^{2,3}$, Emmanuèle Lechapt-Zalcman ${ }^{4}$, Julia Dina ${ }^{5}$, \\ Apolline Kazemi ${ }^{6}$, Renaud Verdon ${ }^{1}$, Emmanuel Mortier ${ }^{7}$ and Arnaud de La Blanchardière ${ }^{1 *}$ \\ 1 Department of Infectious and Tropical Diseases, CHU Côte de Nacre, Caen, France, ${ }^{2}$ Department of Infectious and Tropical \\ Diseases, CHU Toulouse, Toulouse, France, ${ }^{3}$ INSERM U1043 - CNRS UMR 5282, Université Toulouse III, Centre de \\ Physiopathologie Toulouse-Purpan, Toulouse, France, ${ }^{4}$ Department of Pathology, CHU Côte de Nacre, Caen, France, \\ ${ }^{5}$ Department of Virology, CHU Côte de Nacre, Caen, France, ${ }^{6}$ Department of Radiology, CHU Côte de Nacre, Caen, France, \\ 'Department of Internal Medicine, Hôpital Louis Mourier, Colombes, France
}

Incidence of progressive multifocal leukoencephalopathy (PML) in HIV-infected patients has declined in the combined antiretroviral therapy (cART) era although a growing number of acquired immunodeficiency syndrome (AIDS)-related PML-immune reconstitution inflammatory syndromes (PML-IRIS) have been published during the same period. Therapeutic management of PML-IRIS is not consensual and mainly relies on corticosteroids. Our main aim was, in addition to provide a thoughtful analysis of published PML-IRIS cases, to assess the benefit of corticosteroids in the management of PML-IRIS, focusing on confirmed cases. We performed a literature review of the 46 confirmed cases of PML-IRIS cases occurring in HIV-infected patients from 1998 to September 2016 (21 unmasking and 25 paradoxical PML-IRIS). AIDS-related PML-IRIS patients were mostly men (sex ratio 4/1) with a median age of 40.5 years (range 12-66). Median CD4 T cell count before cART and at PML-IRIS onset was $45 / \mu \mathrm{l}(0-301)$ and 101/ $\mu$ I (20-610), respectively. After cART initiation, PML-IRIS occurred within a median timescale of 38 days (18-120). Clinical signs were motor deficits (69\%), speech disorders $(36 \%)$, cognitive disorders (33\%), cerebellar ataxia (28\%), and visual disturbances (23\%). Brain MRI revealed hyperintense areas on T2-weighted sequences and FLAIR images (76\%) and suggestive contrast enhancement (87\%). PCR for John Cunningham virus (JCV) in cerebrospinal fluid (CSF) was positive in only $84 \%$ of cases; however, when performed, brain biopsy confirmed diagnosis of PML in $90 \%$ of cases and demonstrated histological signs of IRIS in 95\% of cases. Clinical worsening related to PML-IRIS and leading to death was observed in $28 \%$ of cases. Corticosteroids were prescribed in $63 \%$ of cases and maraviroc in one case. Statistical analysis failed to demonstrate significant benefit from steroid treatment, despite spectacular improvement in certain cases. Diagnosis of PML-IRIS should be considered in HIV-infected patients with worsening neurological symptoms after initiation or resumption of effective cART, independently 
of CD4 cell count prior to CART. If PCR for JCV is negative in CSF, brain biopsy should be discussed. Only large multicentric randomized trials could potentially demonstrate the possible efficacy of corticosteroids and/or CCR5 antagonists in the management of PML-IRIS.

Keywords: immune reconstitution inflammatory syndrome, progressive multifocal leukoencephalopathy, acquired immunodeficiency syndrome, HIV infection, John Cunningham virus, combined antiretroviral therapy, mortality, corticosteroids

\section{INTRODUCTION}

Progressive multifocal leukoencephalopathy (PML), first described by Astrom in 1958 and finally related to the John Cunningham virus (JCV) by Padgett in 1971, is a rare devastating disease of the CNS caused by the reactivation of JCV in immunocompromised patients (1). PML results in death and loss of the infected oligodendrocytes and their myelin sheaths, leading to a demyelinating disease with bizarre astrocytes and enlarged oligodendrocyte nuclei $(2,3)$. Before the HIV epidemic, PML was exclusively observed in patients with hematological malignancies, organ transplant recipients, or chronic inflammatory disorders with immunosuppressive drugs. Although HIV infection currently accounts for approximately $80 \%$ of new PML cases, PML occurrence related to the use of therapeutic monoclonal antibodies including natalizumab, efalizumab, and rituximab is rising (4). No drug is effective against JCV. Since the restoration of CD4 and CD8 JCV-specific T cell immune responses, allowing the control of JCV replication, the initiation of combined antiretroviral therapy (cART) in HIV-infected patients or the discontinuation of immunosuppressive drugs in non-HIV-infected patients remain the only available therapeutic alternative for PML. Indeed, cART-induced immune recovery improved PML survival in HIV-infected patients from $0-30$ to $38-62 \%$ after 1 year $(1,5)$. However, immune restoration is not always beneficial, and $16.7 \%$ of HIV-infected patients with PML worsen after cART initiation, due to severe neuroinflammation within settings of immune reconstitution inflammatory syndrome (PML-IRIS) (6). Pathophysiology of PML-IRIS implicates a distorted cARTinduced immune restoration of JCV-specific immune responses dominated by cytotoxic CD8 T cells, generating inflammatory CNS tissue damage, neurological deficits, and pronounced mortality and morbidity $(7,8)$. The contribution of IRIS toward the clinical worsening of PML is difficult to distinguish from natural evolution of classical AIDS-associated PML. PML-IRIS diagnosis requires a demonstration of HIV replication control on cART-which is a prerequisite to immune recovery-and of an inflammatory response in the infected brain through the detection of gadolinium enhancement and/or edema or mass effect of PML lesions by MRI, and/or parenchymal infiltration of PML lesions by predominantly CD8 T cells and macrophages in brain biopsies $(9,10)$. Therapeutic management of PML-IRIS usually relies on steroids, despite fears with regard to the use of treatment modalities that may blunt the anti-JCV immune responses that are instrumental in the long-term control of JCV replication $(11,12)$. The aim of this review was to analyze epidemiological, clinical, radiological, biological, pathological, and therapeutic data on confirmed PML-IRIS published in the literature, to assess the benefit of corticosteroids in the management of PML-IRIS, and to provide incentive for future large-scale studies.

\section{METHODS}

A review of the literature in English, French, and Spanish was performed via a computer-based search on PubMed Home by crossing the key words "HIV infection" and "progressive multifocal leukoencephalopathy" with or without "immune reconstitution inflammatory syndrome." Articles were selected for review if their title or abstract suggested that they either reported individual or group data with PML-IRIS diagnosis or performed a review on PML-IRIS in HIV-infected patients. Searches in the reference lists of selected articles led to the identification of further relevant publications. The literature search period ranged from the first case described in 1998 to September 2016. We took care not to list the same case twice.

Diagnosis of AIDS-related PML-IRIS required three major criteria drawn from PML diagnostic criteria as per the AAN consensus statement and CNS-IRIS criteria [2].

- HIV-infected patient

- Criteria for definite PML:

- Subacute onset of neurological deficits

- MRI features

- Presence of JCV DNA in cerebrospinal fluid (CSF) and/or brain tissue.

- Criteria for definite PML-IRIS in adult HIV-infected patients:

- Administration of effective cART within the previous 2 years

- Subacute onset of neurological deficits that either appeared (unmasking-PML-IRIS) or was exacerbated after initiation of cART (paradoxical-PML-IRIS).

- Decrease in plasmatic HIV RNA viral load (VL) of $\geq 1 \log _{10}$ copies/ml with or without an increase in CD4 $\mathrm{T}$ cell count from baseline at the onset or worsening of neurological symptoms.

- Evidence of an inflammatory reaction in the brain demonstrated by MRI (contrast enhancement, edema and/or mass effect) and/or CNS histopathology if available ( $\mathrm{T}$ cell infiltration), to distinguish PML-IRIS from usual progression of previously acquired PML.

We analyzed the following parameters for each case: Epidemiological characteristics, timescale between cART initiation and PML-IRIS onset, clinical presentation, brain MRI 
signs (hypointense lesions in T1-weighted and hyperintense in T2-weighted sequences and FLAIR images), contrast enhancement, edema, mass effect, HIV VL and CD4 T cell count at baseline and PML-IRIS diagnosis, results of PCR for JCV in CSF, detection of JCV and pathological data in brain biopsy, clinical outcome and corticosteroid or other therapy if administered. Statistical analysis was performed using STATA 14 to compare the outcome according to drug therapy with or without corticosteroids. Proportions were compared using the Chi-square test or Fisher's exact test, as appropriate. A p-value of $<0.05$ was considered to be statistically relevant.

\section{RESULTS OF THE LITERATURE REVIEW}

\section{Epidemiology}

Through our literature review from 1998 to September 2016, we identified 157 cases published as having developed "PMLIRIS". Among them, 113 cases were excluded because they did not satisfy the required definite PML-IRIS criteria. We finally identified 46 confirmed and well-described cases of PML-IRIS in HIV-infected patients (9-11, 13-39; Fournier et al., under review $\left.^{1}\right)$. All cases were virologically confirmed-PML. Twenty one (46\%) cases were unmasking PML-IRIS and 25 (54\%) were paradoxical PML-IRIS. Patient characteristics are summarized in Tables 1 and 2 (Tables 1 and 2).

\section{Diagnosis}

Median delay between cART initiation and the onset of unmasking and paradoxical PML-IRIS was 41 and 38 days, respectively. PML-IRIS presented mostly with motor deficits, speech disorders,

${ }^{1}$ Fournier A, Martin-Blondel G, Lechapt-Zalcman E, Dina J, Kazemi A, Verdon R, et al. Two new cases of HIV-related progressive multifocal leukoencephalopathy unmasked or worsened by an immune reconstitution inflammatory syndrome. (Under Review in Frontiers in Immunology).

TABLE 1 | Epidemiological, clinical, and radiological characteristics of the 46 included patients.

\begin{tabular}{lcc}
\hline & Value & N \\
\hline Sex ratio (male/female) & 4 & 42 \\
Median age, years (range) & $40.5[12-66]$ & 38 \\
Median delay between cART and IRIS, days (range) & $38[18-120]$ & 33 \\
Unmasking PML-IRIS & $41[20-120]$ & 14 \\
Paradoxical PML-IRIS & $38[18-120]$ & 19 \\
Clinical features & & \\
Motor deficit (\%) & $27(69 \%)$ & 39 \\
Speech disorders (\%) & $14(36 \%)$ & 39 \\
Cognitive disorders (\%) & $13(33 \%)$ & 39 \\
Cerebellar ataxia (\%) & $11(28 \%)$ & 39 \\
Visual disturbances (\%) & $9(23 \%)$ & 39 \\
Facial paralysis (\%) & $4(10 \%)$ & 39 \\
Seizure (\%) & $3(8 \%)$ & 39 \\
Brain MRI abnormalities & & \\
Hypo intense lesions on T1-weighted and hyper intense & $35(76 \%)$ & 46 \\
lesions on T2-weighted and FLAIR sequences (\%) & & \\
Contrast-enhanced lesions (\%) & $40(87 \%)$ & 46 \\
Edema (\%) & $14(30 \%)$ & 46 \\
Mass effect (\%) & $11(24 \%)$ & 46
\end{tabular}

$N$ : number of data available for characteristic. cognitive disorders, cerebellar ataxia, visual disturbances, facial paralysis, and/or seizures (Table $\mathbf{1}$ ).

All patients underwent brain MRI that revealed contrastenhanced lesions, edema, and mass effect in 87,30 , and $24 \%$ of cases. Only six patients presented none of these signs (Table 1).

Among the cases for which information was available, median HIV VLbefore initiating cART was relatively high $(100,000 \mathrm{cp} / \mathrm{ml})$, declining rapidly thereafter at PML-IRIS onset to $490 \mathrm{cp} / \mathrm{ml}$, with no difference between the two types of PML-IRIS. Likewise, among cases for which information was available, median blood CD4 T cell count before cART was $45 / \mu \mathrm{l}$ (range 0-301), increasing upon diagnosis of PML-IRIS to $101 / \mu \mathrm{l}$ (range 20-610), with no difference between the two types of PML-IRIS (Table 2).

Among the 38 patients who underwent PCR analysis to determine the presence of JCV in the CSF, PCR was positive in $84 \%$ of cases. Among the 21 patients who underwent brain biopsy, 10 (48\%) presented one or more histological signs of PML (multifocal demyelination, oligodendrocytes containing inclusion bodies, enlarged bizarre astrocytes with reactive gliosis), and PML was virologically confirmed for 19 (90\%): 7 by PCR in brain tissue, 7 by immunohistochemical detection and 5 by in situ hybridization (Table 2). When PCR for JCV in CSF and virological studies in brain biopsy were performed simultaneously, presence of JCV was positive in CSF and brain tissue in $5 / 13$ patients (39\%), positive in CSF but negative in brain tissue in $2 / 13$ patients (15\%), and negative in CSF but positive in brain tissue in 6/13 patients (46\%) (Table 2).

Among the 21 patients who underwent brain biopsy, 20 (95\%) presented histological evidence of IRIS, including the 6 patients without contrast enhancement, edema or mass effect on brain MRI (Table 2). Histological features of PML-IRIS were the parenchymal accumulation of $\mathrm{T}$ cells and activated macrophages

TABLE 2 | Biological, virological, and pathological characteristics of the 46 PML-IRIS patients.

\begin{tabular}{|c|c|c|}
\hline & Value & $N$ \\
\hline $\begin{array}{l}\text { Median HIV viral load (VL) before combined } \\
\text { antiretroviral therapy (cART) (/ml) (range) }\end{array}$ & $100,000[29-1,000,000]$ & 31 \\
\hline $\begin{array}{l}\text { Unmasking PML-immune reconstitution } \\
\text { inflammatory syndromes (PML-IRIS) }\end{array}$ & $100,000[40-750,000]$ & 13 \\
\hline Paradoxical PML-IRIS & $125,000[29-1,000,000]$ & 18 \\
\hline Median HIV VL at IRIS onset (/ml) (range) & $490[10-100,000]$ & 30 \\
\hline Unmasking PML-IRIS & $100[40-100,000]$ & 14 \\
\hline Paradoxical PML-IRIS & $710[10-10,000]$ & 16 \\
\hline $\begin{array}{l}\text { Median CD4 T cell count before cART }(/ \mu \mathrm{l}) \\
\text { (range) }\end{array}$ & $45[0-301]$ & 37 \\
\hline Unmasking PML-IRIS & $48[8-301]$ & 18 \\
\hline Paradoxical PML-IRIS & $43[0-284]$ & 19 \\
\hline $\begin{array}{l}\text { Median CD4 T cell count at IRIS onset }(/ \mu \mathrm{l}) \\
\text { (range) }\end{array}$ & 101 [20-610] & 28 \\
\hline Unmasking PML-IRIS & $101[49-464]$ & 10 \\
\hline Paradoxical PML-IRIS & $101[20-610]$ & 18 \\
\hline $\begin{array}{l}\text { Positive PCR for JCV in cerebrospinal } \\
\text { fluid (\%) }\end{array}$ & $32(84 \%)$ & 38 \\
\hline Unmasking PML-IRIS & $17(94 \%)$ & 18 \\
\hline Paradoxical PML-IRIS & $15(75 \%)$ & 20 \\
\hline $\begin{array}{l}\text { Detection of John Cunningham virus in brain } \\
\text { biopsy (\%) }\end{array}$ & $19(90 \%)$ & 21 \\
\hline Pathologically proven PML (\%) & $10(48 \%)$ & 21 \\
\hline Pathologically proven PML-IRIS (\%) & $20(95 \%)$ & 21 \\
\hline
\end{tabular}

$N$, number of data available for characteristic. 
TABLE 3 | Treatment and clinical outcomes of the 46 PML-IRIS patients.

\begin{tabular}{lcc}
\hline & Value & N \\
\hline Treatment & & \\
$\quad$ Corticosteroid (\%) & $29(63 \%)$ & 46 \\
Cidofovir (\%) & $4(9 \%)$ & 46 \\
Maraviroc (\%) & $1(2 \%)$ & 46 \\
Clinical outcome independent of therapy & & 43 \\
Improvement (\%) & $27(63 \%)$ & 43 \\
Stabilization (\%) & $4(9 \%)$ & 43 \\
Death within 2 years (\%) & $12(28 \%)$ & 29 \\
Clinical outcome according to therapy & & 29 \\
With corticosteroids & & \\
$\quad$ Improvement or stabilization (\%) & $21(72 \%)$ & 14 \\
$\quad$ Aggravation then death (\%) & $8(28 \%)$ & 14 \\
Without corticosteroids & & \\
$\quad$ Improvement or stabilization (\%) & $10(71 \%)$ & \\
$\quad$ Aggravation then death (\%) & $4(29 \%)$ & \\
\hline
\end{tabular}

$N$, number of data available for characteristic.

in $12 / 20$ biopsies $(60 \%)$. T cell infiltrates were composed of CD8 $\mathrm{T}$ cells for $12 / 20$ biopsies (60\%). When specified, CD4 T cells were localized in the perivascular compartment without infiltrating the parenchyma. Cells from the $\mathrm{B}$ cell lineage were found in $12 / 20$ cases $(60 \%)$, including CD20 ${ }^{+} \mathrm{B}$ cells for $7 / 20$ cases $(35 \%)$ and $\mathrm{CD} 138^{+}$plasmocytes for $5 / 20$ cases $(25 \%)$. Oligodendrocytes contained JCV inclusion bodies in $8(40 \%)$ cases. Unfortunately, $8 / 20$ (40\%) biopsied cases report only a perivascular infiltrate with T cells without specifying their CD4 or CD8 specificity.

\section{Drug Therapy and Clinical Outcome}

Regarding management of PML-IRIS, 29 of the 46 patients $(63 \%)$ were treated with corticosteroids: methylprednisolone alone in 3 cases (10\%), methylprednisolone then prednisone or dexamethasone in 5 cases (17\%), prednisone or dexamethasone directly in 14 cases (48\%), or an unspecified corticosteroid in 7 cases (24\%) with variable or non-specified modalities for dosage and duration. Among the remaining patients, 4 were treated with cidofovir and 1 with maraviroc (Table 3 ).

Among the 43 patients for whom outcome is detailed with a median follow-up of 8 months (0-101 months), 31 patients (72\%) improved or stabilized, whereas 12 (28\%) worsened then died from PML-IRIS within the 2 years following diagnosis, with no significant difference between unmasking and paradoxical PML-IRIS, respectively, 72 vs 56\% improved, 6 vs $12 \%$ stabilized and 22 vs $32 \%$ died.

Clinical outcome of PML-IRIS did not differ between patients treated or untreated by corticosteroids, whatever be the type of PML-IRIS: 21/29 (72\%) of patients who received corticosteroids had a favorable outcome (improvement or stabilization) vs $10 / 14(71 \%)$ of the patients who did not receive corticosteroids (Table 3).

\section{DISCUSSION}

\section{Epidemiology}

From 1998 to September 2016, we identified in the literature 46 definite cases of HIV-related PML-IRIS. This exhaustive review that aimed to assess the impact of steroids on the outcome of definite AIDS-related PML-IRIS excluded voluntarily cases that could have been considered as unfavorable progression of PML despite cART. We are therefore unable to precise the incidence of PML-IRIS. Because IRIS has only been considered as a distinct clinical condition since the late 1990s, it is likely that many reported cases of PML occurring or worsening after cART initiation were not identified as PML-IRIS. Furthermore, as demonstrated in our review, some cases of PML-IRIS have been histologically documented without brain MRI signs.

If most PML-IRIS patients were severely immunocompromised with a median CD4 cell count before cART of $45 / \mu 1$, the disease may occur in patients with relatively high CD4 cell count before cART initiation (100-300 CD4/ $\mu \mathrm{l})$. In contrast, the modest increase in blood CD4 T cell count after cART at PML-IRIS onset (101 $\mathrm{CD} 4 / \mu \mathrm{l})$ is comparable with the mean CD4 T cell count of $84-104^{\prime} \mu \mathrm{l}$ reported in PML patients before the cART era (2). Meta-regression analysis revealed that a CD4 cell count $<50$ cells/ $\mu$ l upon cART initiation was an independent risk factor for IRIS, independently of the type of opportunistic infection (9). Likewise, Shelburne et al. reported that predictive factors for Mycobacterium tuberculosis, Mycobacterium avium complex, and Cryptococcus neoformansassociated IRIS were antiretroviral drug naivety, active or subclinical opportunistic infection with high antigen burden before cART initiation, CD 4 count $<50$ cells/ $\mu$ l and a rapid initial decrease in HIV VL in response to cART (40). Among AIDS-related PML patients, the only identified risk factor for PML-IRIS is a lower baseline CD4 T cell count (mean 34.8 vs 71.7 for PML) (41).

Among PML-IRIS patients, we observed an almost identical number of cases of unmasking and paradoxical PML-IRIS, whereas diagnostic of unmasking is much more difficult to establish. There was no difference in the median delay between cART initiation and diagnosis of PML-IRIS (41 and 38 days, respectively). In their review of 54 PML-IRIS patients (also including non-definite PML-IRIS cases), Tan et al. observed a trend for paradoxical PML-IRIS to develop IRIS sooner compared to unmasking PML-IRIS after cART initiation (4 vs 8 weeks) (11). In our study, we only observed a trend toward a greater attributable mortality for paradoxical PML-IRIS compared to unmasking PML-IRIS (32 vs 22\%), as did Tan et al. (53 vs $31 \%$ of cases) (11).

\section{Diagnosis}

Strikingly, in our literature review, we had to exclude 113 published cases that failed to fit minimal diagnostic criteria for PML-IRIS and that may have been related to an unfavorable outcome of PML despite cART initiation. Although particularly challenging, differentiating unfavorable outcome of PML from PML-IRIS remains crucial since treatment strategies drastically differ between the two settings. Indeed, PML-IRIS requires therapeutic control of antiviral inflammatory response, whereas PML treatment aims at restoring JCV-specific immune responses to afford viral clearance.

With similar frequencies of motor deficit (69 vs $42 \%$ ), speech disorders (36 vs 40\%), cognitive disorders (33 vs 36\%), cerebellar ataxia (28 vs $29 \%$ ), and visual disturbances (23 vs $19 \%$ ), the clinical presentation of PML-IRIS patients did not differ from PML patients reported in the pre-cART era, with the exception of 
subacute onset of PML-IRIS that is very different from the usual progressive onset of PML (42).

Brain MRI pattern of PML-IRIS with multiple subcortical white matter lesions appearing hypointense on $\mathrm{T} 1$ sequences and hyperintense on $\mathrm{T} 2$ and FLAIR sequences did not differ from PML, except for demonstration of inflammatory features that, although inconstant, remain instrumental clues for PML-IRIS diagnosis $(1,2)$. Rarely associated with PML in the pre-cART era (5-10\%), gadolinium enhancement of PML lesions (87\%), perilesional edema (30\%), and mass effect (24\%) were key findings in published cases (43-45). Although 13\% of these 46 patients had no brain inflammatory features on brain MRI, PML-IRIS was confirmed by histology. Consequently, while contrast enhancement on brain MRI supports PML-IRIS diagnosis, its absence does not preclude it, and diagnosis of PML-IRIS may require brain biopsy $(5,10)$.

In contrast with patients with classical PML who present minimal infiltrates predominantly composed of $\mathrm{CD}^{+} 8^{+}$macrophages/microglial cells with very few T cells, most of the 21 patients with PML-IRIS who underwent brain biopsy displayed a massive accumulation of T cells in PML-IRIS lesions (95\%). These inflammatory infiltrates are dominated by $\mathrm{CD}^{+} \mathrm{T}$ cells, which are almost exclusively composed of $\mathrm{CD}^{+} \mathrm{T}$ cells $(1,2$, $5,24)$, reminiscent of the pathology described in PML-IRIS occurring in non-HIV-infected patients (46). Although a case report suggested the central role of polyfunctional CD4 T cells in natalizumab-associated PML-IRIS, CD4 T cells do not usually infiltrate the CNS parenchyma in HIV-infected patients experiencing PML-IRIS but remain sequestrated in the perivascular vicinity while CD8 $\mathrm{T}$ cells penetrate the parenchyma and interact with JCV-infected oligodendrocytes $(10,47)$. It remains to be determined whether the infiltrating CD8 T cells are solely directed against JCV or are specific for other (self-) antigens in the context of a dysregulated T-cell response, although physical contact of CD8 T cells expressing Granzyme B in close apposition to JCV-infected oligodendrocytes point toward a role for JCVspecific CD8 T cells.

Although essential for PML-IRIS diagnosis when brain MRI is not contributive, potential complications of brain biopsy nevertheless stress the need for an alternative diagnostic marker.

In such conditions, proton magnetic resonance spectroscopy could be of interest in demonstrating specific modifications. In particular, it was shown that Lipid1/Creatin ratio is elevated in PML-IRIS lesions independently of contrast enhancement, representing a surrogate marker for PML-IRIS, but only myoinositol/creatine remains elevated in lesions of patients with PML-IRIS over time (34). Others authors underlined an additional increase of choline and lactate/lipids in a case report using stereotactic brain biopsy for confirmed PML-IRIS compared with the spectrum of PML acquired before cART (48). The hypoperfusion of brain PML lesions determined by arterial spin labeling MRI was significantly greater in PML progressors than in survivors and is inversely correlated to the occurrence of PML-IRIS in one interesting study that deserves confirmation (49). Finally, although monitoring changes in the numbers or in the functional profile of circulating JCV-specific CD4 and CD8 $\mathrm{T}$ cells after initiating cART appeared promising for
PML-IRIS diagnosis, PML-IRIS was not consistently associated with a higher frequency of circulating JCV-specific CD4 or CD8 $\mathrm{T}$ cells, suggesting that other $\mathrm{T}$ cell subsets play a role in the pathogenesis of PML-IRIS (50).

A consensual diagnostic statement for PML-IRIS based on a multiparametric assessment is still lacking, but urgently needed. Here, we propose such a definition, adapted from Tan $\mathrm{K}$ et al., which should be validated in further studies (Table 4) (11).

\section{Prognosis and Drug Therapy}

Although survival of patients with PML has improved over recent years, thanks to earlier recognition, improvement in diagnostic techniques, and the widespread use of cART, the mortality rate reaches around $50 \%$ of $\mathrm{HIV}$-infected patients developing PML $(51,52)$. In our literature review, we observed a $28 \%$ mortality rate of PML patients developing IRIS. Several retrospective observational studies have demonstrated the absence of any significant difference in survival between PML with and without IRIS $(53,54)$. In the absence of any effective anti-JCV treatment, PML outcomes indeed depend entirely on the individual's capacity to recover the JCV-specific immune responses that can control viral replication. In HIV-infected patients, cART is the only therapeutic alternative with a proven benefit on PML outcome, with the risk of developing IRIS in a subset of patients as a testimony of the immune system's ability to control JCV replication and to improve PML outcome (55).

However, PML-IRIS can, in rare cases, become a severe and life-threatening condition while its management using corticosteroids and/or any other immune modulatory therapy remains non-consensual. Steroids have been used and may be effective in IRIS following AIDS-related CNS infections caused by mycobacteria, cryptococci, and cytomegalovirus (41). Corticosteroids have, in certain cases, been successfully used for catastrophic PML-IRIS (massive inflammation resulting in impending brain herniation) at a high and early intravenous dosage and over a long duration, but with no apparent difference in the duration of survival for surviving patients, or time to death for deceased patients $(11,21,30,56)$. On the other side, a potentially deleterious role of corticosteroids on long-term anti-JCV immune responses has been raised (12). Our work that included only definite PML-IRIS patients in order to exclude PML patients potentially misclassified as PML-IRIS does not demonstrate a potential benefit of corticosteroids on the prognosis of HIV-related PML-IRIS, nor a deleterious effect, possibly due to the small number of cases.

Alternative therapeutic strategies that selectively alleviate inflammation without hampering immune restoration are

\section{TABLE 4 | Proposed diagnostic criteria for AIDS-related PML-IRIS.}

(i) HIV infection

(ii) Close temporal relationship between cART initiation and disease onset

(iii) CART resulting in a decrease in plasma HIV VL $>1 \log _{10}$ at the onset or worsening of neurological symptoms

(iv) Diagnosis of PML by detection of JCV DNA in CSF or brain tissue

(v) Evidence of an inflammatory reaction demonstrated by MRI and/or CNS histopathology

(vi) Symptoms could not be explained by a newly acquired infection, the expected course of PML or another opportunistic infection or drug toxicity 
therefore desirable. Recent insights arising from the management of inflammatory forms of PML in IRIS settings suggest the role of the CCR5-CCL5 axis in PML-IRIS pathogenesis (57). A dramatic clinical improvement experienced by an HIVinfected patient developing PML-IRIS - a case which could not be included in our review-was reported when maraviroc, an antagonist of CCR5, was added to ART (58). It was suggested that maraviroc may have reduced the severity of neuroinflammation related to IRIS by targeting $\mathrm{CCR}^{+}$leukocyte recruitment to the CNS (59). This concept was also strengthened by a telling case report of a woman with multiple sclerosis, who developed natalizumab-associated PML and who benefited from the preventive and curative properties of maraviroc for PML-IRIS. In addition, a selective reduction in the proportions of CCR5 ${ }^{+} \mathrm{T}$ cells in CSF was observed while the patient was receiving maraviroc, suggesting that CCR5 antagonists may selectively limit immune cell trafficking into the CNS in vivo (60). These observations were further developed, showing that the vast majority of $\mathrm{CD}^{+} \mathrm{T}$ cells infiltrating PML-IRIS lesions, the likely drivers of tissue damage, express high levels of CCR5 $(59,61)$. Building on these observations, it was suggested that CCR5 might be implicated in the pathogenesis of PML-IRIS, hence warranting further studies. The single patient in our review who received maraviroc and the very few contradictory published case reports prevent us from drawing conclusions on the potential immunomodulatory benefits of maraviroc in inflammatory PML settings $(29,38,58,60)$. Worthy of note, the double-blinded randomized placebo-controlled CADIRIS trial showed that the addition of maraviroc to CART did not reduce the risk of IRIS in 276 patients with advanced HIV infection (62). However, this study included a heterogeneous cohort of patients with IRIS, with only very few opportunistic infections affecting the CNS, precluding the generalization of its conclusions to IRIS affecting the CNS.

Therefore, in the absence of clinical multicentric randomized trials, no recommendations can be made on the use of corticosteroids and/or maraviroc in the management of PML-IRIS. However, we believe that steroids should be reserved for PMLIRIS patients with severe neurological symptoms and/or massive inflammation with cerebral edema or even brain herniation (11, $21,30,56)$ and not be used when patients only displayed contractenhanced lesions on brain MRI without a clinical worsening related to this inflammatory reaction. Preclinical studies aimed at delineating the behavior of $\mathrm{CCR} 5^{+} \mathrm{JC}$-virus-specific T cells in blood and CSF are needed to support clinical trials assessing

\section{REFERENCES}

1. Tan CS, Koralnik IJ. Progressive multifocal leukoencephalopathy and other disorders caused by JC virus: clinical features and pathogenesis. Lancet Neurol (2010) 9:425-37. doi:10.1016/S1474-4422(10)70040-5

2. Berger JR, Aksamit AJ, Clifford DB, Davis L, Koralnik IJ, Sejvar JJ, et al. PML diagnostic criteria: consensus statement from the AAN neuroinfectious disease section. Neurology (2013) 80:1430-8. doi:10.1212/WNL.0b013e31828c2fa1

3. Astrom KE, Mancall EL, Richardson EP Jr. Progressive multifocal leukoencephalopathy; a hitherto unrecognized complication of chronic lymphatic leukaemia and Hodgkin disease. Brain (1958) 81:93-111. the impact of CCR5 antagonists in the context of inflammatory PML (57).

\section{CONCLUSION}

Although classical PML has declined with cART, PML-IRIS now accounts for up to $25 \%$ of PML cases diagnosed in HIV-infected patients during the cART era. Diagnosis of PML-IRIS should be considered in any HIV-infected patient developing unexplained neurological disorders or worsening of a previously diagnosed PML 2 weeks to 4 months after the initiation or resumption of effective cART, independently of the CD4 cell count prior to cART. Brain MRI is instrumental by demonstrating inflammatory features of PML lesions and could be complemented by brain biopsy in the absence of contrast-enhanced lesions. Although it can be severe, the outcome of AIDS-related PML does not seem to be worsened by IRIS, which, instead, is a testimony of a protective immune response that is instrumental in the long term of JCV replication. Our current perception of this neuroinflammatory disease supports therapeutic strategies aimed at modulating immune aggression without dampening the life-saving restoration of the immune response. No definite conclusion can be drawn on the efficacy of steroids, although case reports suggest that early corticosteroid therapy may be proposed for life-threatening PML-IRIS. There is an urgent need for randomized multicentric trials using corticosteroids and/or maraviroc to improve prognosis of AIDS-related PML-IRIS. Future studies should also be designed to better delineate pathophysiological mechanisms underlying PML-IRIS and identify plasmatic and/ or CSF biomarkers of this difficult to diagnose entity.

\section{ETHICS STATEMENT}

Since this study was only a review, it did not require ethical approval.

\section{AUTHOR CONTRIBUTIONS}

$\mathrm{AF}$ and $\mathrm{AB}$ designed the study, collected and analyzed data, and drafted the manuscript. GM-B participated in manuscript drafting. AF performed statistical analysis. All authors critically commented on the paper, contributed toward and approved the final manuscript.

\section{FUNDING}

Neither the authors nor their institutions received payment or services from a third party for any aspect of the submitted work.

4. Carson KR, Focosi D, Major EO, Petrini M, Richey EA, West DP, et al. Monoclonal antibody-associated progressive multifocal leukoencephalopathy in patients treated with rituximab, natalizumab, and efalizumab: a review from the research on adverse drug events and reports (RADAR) project. Lancet Oncol (2009) 10:816-24. doi:10.1016/S14702045(09)70161-5

5. Cinque P, Koralnik IJ, Gerevini S, Miro JM, Price RW. Progressive multifocal leukoencephalopathy in HIV-1 infection. Lancet Infect Dis (2009) 9:625-36. doi:10.1016/S1473-3099(09)70226-9

6. Müller M, Wandel S, Colebunders R, Attia S, Furrer H, Egger M, et al. Immune reconstitution inflammatory syndrome in patients starting antiretroviral 
therapy for HIV infection: a systematic review and meta-analysis. Lancet Infect Dis (2010) 1:251-61. doi:10.1016/S1473-3099(10)70026-8

7. Marzocchetti A, Di Giambenedetto S, Cingolani A, Ammassari A, Cauda R, De Luca A. Reduced rate of diagnostic positive detection of JC virus DNA in cerebrospinal fluid in cases of suspected progressive multifocal leukoencephalopathy in the era of potent antiretroviral therapy. J Clin Microbiol (2005) 43:4175-7. doi:10.1128/JCM.43.8.4175-4177.2005

8. Martin-Blondel G, Mars LT, Liblau RS. Pathogenesis of the immune reconstitution inflammatory syndrome in HIV-infected patients. Curr Opin Infect Dis (2012) 25:312-20. doi:10.1097/QCO.0b013e328352b664

9. Gray F, Bazille C, Adle-Biassette H, Mikol J, Moulignier A, Scaravilli F. Central nervous system immune reconstitution disease in acquired immunodeficiency syndrome patients receiving highly active antiretroviral treatment. J Neurovirol (2005) 11(S3):16-22. doi:10.1080/13550280500511741

10. Martin-Blondel G, Bauer J, Cuvinciuc V, Uro-Coste E, Debard A, Massip P, et al. In situ evidence of JC virus control by CD8+ T cells in PML-IRIS during HIV infection. Neurology (2013) 81:964-70. doi:10.1212/WNL. 0b013e3182a43e6d

11. Tan K, Roda R, Ostrow L, McArthur J, Nath A. PML-IRIS in patients with HIV infection clinical manifestations and treatment with steroids. Neurology (2009) 72:1458-64. doi:10.1212/01.wnl.0000343510.08643.74

12. Antoniol C, Jilek S, Schluep M, Mercier N, Canales M, Le Goff G, et al. Impairment of JCV-specific T-cell response by corticotherapy Effect on PML-IRIS management? Neurology (2012) 79:2258-64. doi:10.1212/WNL. 0b013e3182768983

13. Cinque P, Bossolasco S, Brambilla AM, Boschini A, Mussini C, Pierotti C, et al. The effect of highly active antiretroviral therapy-induced immune reconstitution on development and outcome of progressive multifocal leukoencephalopathy: study of 43 cases with review of the literature. J Neurovirol (2003) 9(S1):73-80. doi:10.1080/713831417

14. Vidal JE, Oliveira AC, Fink MC, Pannuti CS, Trujillo JR. AIDS-related progressive multifocal leukoencephalopathy: a retrospective study in a referral center in São Paulo, Brazil. Rev Inst Med Trop Sao Paulo (2008) 50:209-12. doi:10.1590/S0036-46652008000400004

15. Kotecha N, George MJ, Smith TW, Corvi F, Litofsky NS. Enhancing progressive multifocal leukoencephalopathy: an indicator of improved immune status? Am J Med (1998) 105:541-3. doi:10.1016/S0002-9343(98)00321-0

16. Tantisiriwat W, Tebas P, Clifford DB, Powderly WG, Fichtenbaum CJ. Progressive multifocal leukoencephalopathy in patients with AIDS receiving highly active antiretroviral therapy. Clin Infect Dis (1999) 28:1152-4. doi:10.1086/514762

17. Miralles P, Berenguer J, Lacruz C, Cosín J, López JC, Padilla B, et al. Inflammatory reactions in progressive multifocal leukoencephalopathy after highly active antiretroviral therapy. AIDS (2001) 15:1900-2. doi:10.1097/00002030-200109280-00028

18. Razonable RR, Aksamit AJ, Wright AJ, Wilson JW. Cidofovir treatment of progressive multifocal leukoencephalopathy in a patient receiving highly active antiretroviral therapy. Mayo Clin Proc (2001) 76:1171-5. doi:10.4065/ 76.11.1171

19. Safdar A, Rubocki RJ, Horvath JA, Narayan KK, Waldron RL. Fatal immune restoration disease in human immunodeficiency virus type 1-infected patients with progressive multifocal leukoencephalopathy: impact of antiretroviral therapy-associated immune reconstitution. Clin Infect Dis (2002) 35:1250-7. doi:10.1086/344056

20. Hoffmann C, Horst HA, Albrecht H, Schlote W. Progressive multifocal leucoencephalopathy with unusual inflammatory response during antiretroviral treatment. J Neurol Neurosurg Psychiatry (2003) 74:1142-4. doi:10.1136/ jnnp.74.8.1142

21. Nuttall JJ, Wilmshurst JM, Ndondo AP, Yeats J, Corcoran C, Hussey GD, et al. Progressive multifocal leukoencephalopathy after initiation of highly active antiretroviral therapy in a child with advanced human immunodeficiency virus infection: a case of immune reconstitution inflammatory syndrome. Pediatr Infect Dis J (2004) 23:683-5. doi:10.1097/01. inf.0000130954.41818.07

22. Di Giambenedetto S, Vago G, Pompucci A, Scoppettuolo G, Cingolani A, Marzocchetti A, et al. Fatal inflammatory AIDS-associated PML with high CD4 counts on HAART: a new clinical entity? Neurology (2004) 63:2452-3. doi:10.1212/01.WNL.0000148585.41802.6C
23. Wyen C, Hoffmann C, Schmeier N, Wöhrmann A, Qurishi N, Rockstroh J, et al. Progressive multifocal leukencephalopathy in patients on highly active antiretroviral therapy: survival and risk factors of death. J Acquir Immune Defic Syndr (2004) 37:1263-8. doi:10.1097/01.qai.0000136093.47316.f3

24. Vendrely A, Bienvenu B, Gasnault J, Thiebault JB, Salmon D, Gray F. Fulminant inflammatory leukoencephalopathy associated with HAART-induced immune restoration in AIDS-related progressive multifocal leukoencephalopathy. Acta Neuropathol (2005) 109:449-55. doi:10.1007/s00401-005-0983-y

25. Kastrup O, Wanke I, Esser S, Maschke M. Evolution of purely infratentorial PML under HAART - negative outcome under rapid immune reconstitution. Clin Neurol Neurosurg (2005) 107:509-13. doi:10.1016/j.clineuro.2004.10.005

26. Wyen C, Lehmann C, Fätkenheuer G, Hoffmann C. AIDS-related progressive multifocal leukoencephalopathy in the era of HAART: report of two cases and review of the literature. AIDS Patient Care STDS (2005) 19:486-94. doi:10.1089/apc.2005.19.486

27. Martinez JV, Mazziotti JV, Efron ED, Bonardo P, Jordan R, Sevlever G, et al. Immune reconstitution inflammatory syndrome associated with PML in AIDS: a treatable disorder. Neurology (2006) 67:1692-4. doi:10.1212/01. wnl.0000242728.26433.12

28. Venkataramana A, Pardo CA, McArthur JC, Kerr DA, Irani DN, Griffin JW, et al. Immune reconstitution inflammatory syndrome in the CNS of HIV-infected patients. Neurology (2006) 67:383-8. doi:10.1212/01.wnl. 0000227922.22293 .93

29. Rodríguez M, Silva-Sánchez FA, Luna-Rivero $C$, Vega-Barrientos $R$, Alvarado-de la Barrera C, Reyes-Terán G. Maraviroc failed to control progressive multifocal leukoencephalopathy-associated IRIS in a patient with advanced HIV Infection. Case Rep Med (2014) 2014:381480. doi:10.1155/2014/ 381480

30. Ch'ng TW, Dieudonne A. Immune reconstitution inflammatory syndrome associated with progressive multifocal leukoencephalopathy in a perinatally acquired human immunodeficiency virus-infected young adult. Pediatr Infect Dis J (2007) 26:1068-70. doi:10.1097/INF.0b013e31812e62fa

31. Imamura E, Yamashita H, Fukuhara T, Sawa H, Nagashima K, Kuwabara M, et al. Case of highly active anti-retroviral therapy-induced immune reconstitution inflammatory syndrome in AIDS-related progressive multifocal leukoencephalopathy. Rinsho Shinkeigaku (2007) 47:650-6.

32. Travis J, Varma A, du Plessis D, Turnbull I, Vilar FJ. Immune reconstitution associated with progressive multifocal leukoencephalopathy in human immunodeficiency virus: a case discussion and review of the literature. Neurologist (2008) 14:321-6. doi:10.1097/NRL.0b013e31816e2f13

33. Sidhu N, McCutchan JA. Unmasking of PML by HAART: unusual clinical features and the role of IRIS. J Neuroimmunol (2010) 219:100-4. doi:10.1016/j. jneuroim.2009.11.013

34. Gheuens S, Ngo L, Wang X, Alsop DC, Lenkinski RE, Koralnik IJ. Metabolic profile of PML lesions in patients with and without IRIS. An observational study. Neurology (2012) 79:1041-8. doi:10.1212/WNL.0b013e318268465b

35. Guevara-Silva EA, Ramírez-Crescencio MA, Soto-Hernández JL, Cárdenas G. Central nervous system immune reconstitution inflammatory syndrome in AIDS: experience of a Mexican neurological centre. Clin Neurol Neurosurg (2012) 114:852-61. doi:10.1016/j.clineuro.2012.01.020

36. Kurukumbi M, Steiner S, Dunlap S, Chapman S, Solieman N, Jayam-Trouth A. A rare case of immune reconstitution inflammatory syndrome development in an immunocompromised patient with progressive multifocal leukoencephalopathy and multicentric Castleman's disease. Case Rep Neurol Med (2013) 2013:460701. doi:10.1155/2013/460701

37. Augusto L, Neves N, Reis C, Abreu C, Sarmento A. Clinical and radiological characterization of progressive multifocal leukoencephalopathy in HIVInfected patients: a retrospective analysis and review of the literature. Acta Med Port (2015) 28:286-96. doi:10.20344/amp.5950

38. Shahani L, Shah M, Tavakoli-Tabasi S. Immune reconstitution inflammatory syndrome in a patient with progressive multifocal leukoencephalopathy. BMJ Case Rep (2015). doi:10.1136/bcr-2014-207325

39. Sainz-de-la-Maza S, Casado JL, Pérez-Elías MJ, Moreno A, Quereda C, Moreno S, et al. Incidence and prognosis of immune reconstitution inflammatory syndrome in HIV-associated progressive multifocal leucoencephalopathy. Eur J Neurol (2016) 23:919-25. doi:10.1111/ene.12963

40. Shelburne SA, Visnegarwala F, Darcourt J, Graviss EA, Giordano TP, White AC Jr, et al. Incidence and risk factors for immune reconstitution 
inflammatory syndrome during highly active antiretroviral therapy. AIDS (2005) 19:399-406. doi:10.1097/01.aids.0000161769.06158.8a

41. Shelburne SA III, Hamill RJ. The immune reconstitution inflammatory syndrome. AIDS Rev (2003) 5:67-79.

42. Berger JR, Pall L, Lanska D, Whiteman M. Progressive multifocal leukoencephalopathy in patients with HIV infection. J Neurovirol (1998) 4:59-68. doi:10.3109/13550289809113482

43. Post MJ, Thurnher MM, Clifford DB, Nath A, Gonzalez RG, Gupta RK, et al. CNS-immune reconstitution inflammatory syndrome in the setting of HIV infection, part 1: overview and discussion of progressive multifocal leukoencephalopathy-immune reconstitution inflammatory syndrome and cryptococcal-immune reconstitution inflammatory syndrome. AJNR Am J Neuroradiol (2013) 34:1297-307. doi:10.3174/ajnr.A3183

44. Moulignier A, Mikol J, Pialoux G, Fénelon G, Gray F, Thiebaut JB. AIDSassociated progressive multifocal leukoencephalopathy revealed by new-onset seizures. Am J Med (1995) 99:64-8. doi:10.1016/S0002-9343(99)80106-5

45. Whiteman ML, Post MJ, Berger JR, Tate LG, Bell MD, Limonte LP. Progressive multifocal leukoencephalopathy in 47 HIV-seropositive patients: neuroimaging with clinical and pathologic correlation. Radiology (1993) 187:233-40. doi:10.1148/radiology.187.1.8451420

46. Metz I, Radue EW, Oterino A, Kümpfel T, Wiendl H, Schippling S, et al. Pathology of immune reconstitution inflammatory syndrome in multiple sclerosis with natalizumab-associated progressive multifocal leukoencephalopathy. Acta Neuropathol (2012) 123:235-45. doi:10.1007/s00401-011-0900-5

47. Aly L, Yousef S, Schippling S, Jelcic I, Breiden P, Mathscke J, et al. Central role of JC virus-specific CD4+ lymphocytes in progressive multifocal leucoencephalopathy-immune reconstitution inflammatory syndrome. Brain (2011) 134:2687-702. doi:10.1093/brain/awr206

48. Cuvinciuc V, Martin-Blondel G, Marchou B, Bonneville F. Proton MR spectroscopy of progressive multifocal leucoencephalopathy - immune reconstitution inflammatory syndrome. Am J Neuroradiol (2010) 31:E69-70. doi:10.3174/ajnr.A2160

49. Khoury MN, Gheuens S, Ngo L, Wang X, Alsop DC, KoralnikIJ. Hyperperfusion in progressive multifocal leukoencephalopathy is associated with disease progression and absence of immune reconstitution inflammatory syndrome. Brain (2013) 136:3441-50. doi:10.1093/brain/awt268

50. Gheuens S, Bord E, Kesari S, Simpson DM, Gandhi RT, Clifford DB, et al. Role of $\mathrm{CD} 4+$ and $\mathrm{CD} 8+$, T-cell responses against JC virus in the outcome of patients with progressive multifocal leucoencephalopathy (PML) and PML with immune reconstitution inflammatory syndrome. J Virol (2011) 85:7256-63. doi:10.1128/JVI.02506-10

51. Gasnault J, Taoufik Y. New trends in progressive multifocal leucoencephalopathy. Rev Neurol (Paris) (2006) 162:43-56. doi:10.1016/S0035-3787(06)74981-5

52. Ferenczy MW, Marshall LJ, Nelson CD, Atwood WJ, Nath A, Khalili K, et al. Molecular biology, epidemiology, and pathogenesis of progressive multifocal leukoencephalopathy, the JC virus-induced demyelinating disease of the human brain. Clin Microbiol Rev (2012) 25:471-506. doi:10.1128/ CMR.05031-11

53. Falcó V, Olmo M, del Saz SV, Guelar A, Santos JR, Gutiérrez M, et al. Influence of HAART on the clinical course of HIV-1-infected patients with progressive multifocal leukoencephalopathy: results of an observational multicenter study. J Acquir Immune Defic Syndr (2008) 49:26-31. doi:10.1097/ QAI.0b013e31817bec64

54. Harrison DM, Newsome SD, Skolasky RL, McArthur JC, Nath A. Immune reconstitution is not a prognostic factor in progressive multifocal leukoencephalopathy. J Neuroimmunol (2011) 238:81-6. doi:10.1016/j. jneuroim.2011.07.003

55. Pavlovic D, Patera AC, Nyberg F, Gerber M, Liu M; Progressive Multifocal Leukeoncephalopathy Consortium. Progressive multifocal leukoencephalopathy: current treatment options and future perspectives. Ther Adv Neurol Disord (2015) 8:255-73. doi:10.1177/1756285615602832

56. Johnson T, Nath A. Neurological complications of immune reconstitution in HIV-infected populations. Ann N Y Acad Sci (2010) 1184:106-20. doi:10.1111/ j.1749-6632.2009.05111.x

57. Martin-Blondel G, Brassat D, Bauer J, Lassmann H, Liblau RS. CCR5 blockade for neuroinflammatory diseases - beyond control of HIV. Nat Rev Neurol (2016) 12:95-105. doi:10.1038/nrneurol.2015.248

58. Martin-Blondel G, Cuzin L, Delobel P, Cuvinciuc V, Dumas H, Alvarez M, et al. Is maraviroc beneficial in paradoxical progressive multifocal leukoencephalopathy-immune reconstitution inflammatory syndrome management? AIDS (2009) 23:2545-6. doi:10.1097/QAD.0b013e32833365f4

59. Martin-Blondel G, Bauer J, Uro-Coste E, Biotti D, Averseng-Peaureaux D, Fabre N, et al. Therapeutic use of CCR5 antagonists is supported by strong expression of CCR5 on CD8+ T cells in progressive multifocal leukoencephalopathy-associated immune reconstitution inflammatory syndrome. Acta Neuropathol (2015) 129:463-5. doi:10.1007/s00401-015-1383-6

60. Giacomini PS, Rozenberg A, Metz I, Araujo D, Arbour N, Bar-Or A. Maraviroc and JC virus-associated immune reconstitution inflammatory syndrome. $N$ Engl J Med (2014) 370:486-8. doi:10.1056/NEJMc1304828

61. Stork L, Brück W, Bar-Or A, Metz I. High CCR5 expression in natalizumab-associated progressive multifocal leukoencephalopathy immune reconstitution inflammatory syndrome supports treatment with the CCR5 inhibitor maraviroc. Acta Neuropathol (2015) 129:467-8. doi:10.1007/ s00401-015-1391-6

62. Sierra-Madero JG, Ellenberg SS, Rassool MS, Tierney A, BelaunzaránZamudio PF, López-Martínez A, et al. Effect of the CCR5 antagonist maraviroc on the occurrence of immune reconstitution inflammatory syndrome in HIV (CADIRIS): a double-blind, randomised, placebo-controlled trial. Lancet HIV (2014) 2:e60-7. doi:10.1016/S2352-3018(14)70027-X

Conflict of Interest Statement: The authors declare that the research was con-ducted in the absence of any commercial or financial relationships that could be construed as a potential conflict of interest.

Copyright (c) 2017 Fournier, Martin-Blondel, Lechapt-Zalcman, Dina, Kazemi, Verdon, Mortier and de La Blanchardière. This is an open-access article distributed under the terms of the Creative Commons Attribution License (CC BY). The use, distribution or reproduction in other forums is permitted, provided the original author(s) or licensor are credited and that the original publication in this journal is cited, in accordance with accepted academic practice. No use, distribution or reproduction is permitted which does not comply with these terms. 